\title{
Assessing capacity loss remediation methods for asymmetric redox flow battery chemistries using levelized cost of storage
}

\author{
Kara E. Rodby ${ }^{1}$, Mike L. Perry ${ }^{2}$, Fikile R. Brushett ${ }^{1, *}$ \\ ${ }^{I}$ Department of Chemical Engineering, Massachusetts Institute of Technology, Cambridge, MA, U.S.A. \\ ${ }^{2}$ Vionx Energy Corporation, Woburn, MA, U.S.A. \\ *Corresponding Author: Fikile R. Brushett (brushett@mit.edu)
}

\begin{abstract}
$\underline{\text { Abstract }}$
Redox flow batteries, a promising grid-scale energy storage solution, have an open architecture that can facilitate a broad range of redox electrolytes. Vanadium is the most mature chemistry, which is largely due to its symmetry, where all active species are based on a single parent compound, that allows for inexpensive crossover remediation via rebalancing; however, the industry has increasingly sought chemistries with lower-cost and higher-abundance redox couples. Most chemistries cannot be configured symmetrically, though, necessitating research into capacity-recovery methods for asymmetric chemistries. In this work, we adapt our previously developed levelized cost of storage model, which tracks capacity fade and recovery and evaluates the costs across the battery's lifetime, to analyze two classes of asymmetric chemistries, those with active species of finite or infinite lifetimes, and their respective remediation options. For finitelifetime chemistries, we explore active-species replacement to counter decay. For infinite-lifetime chemistries, we consider two methods for addressing crossover: imposition of pseudo-symmetry via the spectator strategy and elimination of crossover via membranes with perfect selectivity. We anticipate this framework will help guide the evaluation and design of new redox chemistries, balancing the desire for low capital costs with the need to remediate capacity repeatedly and inexpensively.
\end{abstract}

Key words: Redox flow battery, capacity recovery, electrolyte rebalancing, levelized cost of energy stored, spectator strategy, ceramic membrane 


\section{Introduction}

High levels of renewable energy penetration in the grid $(>60 \%)$ are likely to be impractical without the development of complementary strategies to combat intermittency and meet demand, such as integration of energy storage $[1,2]$. No single technology can economically perform the vast array of grid services that, among other factors, vary in response and discharge timescales as well as total capacity requirements, necessitating a diverse portfolio of solutions $[3,4]$. Redox flow batteries (RFBs) store charge in liquid electrolytes that are pumped from external reservoirs through separate half-cells of an electrochemical reactor [5]. This open architecture enables independent scaling of power and energy components (i.e., the electrochemical stack and the electrolyte tanks, respectively) [6], which allows for economic benefits including the decrease of capital costs on a per unit energy basis at longer durations $[7,8]$ and long-term cost savings through component-specific maintenance to extend the battery lifetime and remediate decay [9].

The unique architecture of RFBs enables excellent resiliency for maintaining their energy capacities. However, one must minimize the transport of active species through the semipermeable membranes separating the positive and negative electrodes, which are designed to allow for transport of supporting ions to maintain charge balance [10]. If these membranes are not perfectly selective for the desired charge-carrier species, then RFBs experience capacity reductions via undesired permeation of active species, often referred to as crossover [11]. While crossover is not the sole cause of capacity decline within RFBs, it is often the largest contributor and may halve the accessible capacity within 100-200 cycles [12]. One strategy for mitigating the effects of crossover is the use of a "symmetric" redox chemistry, where all active species are based on a single parent compound [13]. In this case, crossover does not lead to cross-contamination and associated capacity losses are recoverable via periodic electrolyte rebalancing: the transfer and mixing of partial or full volumes of electrolyte between the two reservoirs to balance the concentrations of active species. Rebalancing is a powerful capacity-remediation tool, as it allows the electrolyte to be used indefinitely, assuming other non-crossover capacity losses can be managed and/or remediated as well, which significantly reduces maintenance costs [14]. A number

of symmetric chemistries have been contemplated for RFBs leveraging inorganic [15], organic [16-19], and organometallic [20-22] active species, but vanadium remains the canonical example. 
Vanadium RFBs (VRFBs) are the most researched and commercialized RFB technology, primarily because vanadium has four stable and soluble oxidation states accessible within the electrochemical stability window of aqueous acidic electrolytes on carbon electrodes. This, in turn, allows for a symmetric chemistry $\left(\mathrm{V}^{2+} / \mathrm{V}^{3+}\right.$ in the negative half-cell and $\mathrm{V}^{4+} / \mathrm{V}^{5+}$ in the positive half-cell) and continual recovery of crossover capacity losses via rebalancing. While the VRFB system benefits from reduced maintenance costs, it suffers from a high upfront cost, due, in part, to the price of the active species $[23,24]$. Vanadium prices have been relatively volatile since the 1980 's, and especially so in the last four years with a late 2018 peak of over ten-fold the price at the start of 2016 [25]. The volatility has been attributed to: 1) the limited geographic locations of vanadium mines that leave the few countries that contain them (mainly China, Russia, and South Africa) with a strong control over the global vanadium supply [26], 2) new steel rebar standards that require increased vanadium content (already, 90\% of current vanadium demand is steel [27]), and 3) decreases in supply due to mine closures [28]. The magnitude and uncertainty of vanadium prices is considered a key impediment to broad deployment, which has motivated research into alternative chemistries based on lower-cost and widely-available materials [29-31].

In recent years, the literature has seen a surge of new, potentially-inexpensive, and usually asymmetric RFB chemistries, necessitating consideration of how one might execute asymmetric electrolyte maintenance. Since asymmetric chemistries utilize different active species in the positive and negative half-cells, active species crossover results in cross-contamination. With these chemistries, capacity-loss remediation is expected to be a more challenging and chemistrydependent problem whose technical and economic consequences remain largely unarticulated in the open literature. A recent perspective by Perry et al. describes potential approaches for mitigating and remediating capacity losses due to crossover [14]. The options for crossover remediation depend on the fate of the active species upon entering the opposing half-cell; crossover can either be "destructive," where the active species are unstable in the chemical and electrochemical environment of the opposing half-cell and thus results in non-recoverable losses, or "non-destructive," where the active species remain intact in the opposing half-cell [14]. Destructive crossover remediation requires actives species replacement, but the authors note that there are no known RFB chemistries that experience destructive crossover in the published literature and thus do not explore this technique. What is more common, however, is timedependent (i.e., not crossover-dependent) active species decay in either half-cell, which would also 
necessitate active-species replacement [30]. In this work we divide the asymmetric chemistries and their remediation methods not by the stability of the active species upon crossover, but rather by the general stability or lifetime of the active species in their intended chemical and electrochemical environment, of which we note two classes: infinite and finite lifetime.

Finite-lifetime species experience decay and thus may require periodic replenishment or replacement. These species are generally organic compounds, which, despite uncertainty in their long-term stability, are attractive for RFBs as they are expected to be low-cost [32] and their properties can be tuned through molecular functionalization; for example, increasing molecular size lowers crossover rates due to increased steric hindrance [33]. Recent studies have shown that molecular decay rates of organics in RFB electrolytes are time-dependent and a function of the chemical, thermal, and electrochemical environment [34]. In particular, decay is generally accelerated when the molecule is in the "energized" state (for RFBs, this is the oxidized and reduced states for the positive and negative electrolytes, respectively) [30,35]. There is ongoing research into organic active species with longer lifetimes and techniques to optimize operating conditions to mitigate decay [36-38]. However, to the best of our knowledge, methodologies for removing and replacing decayed active species have not yet been systematically explored, likely due to the nascence of this particular class of chemistries. Note that the addition of active species without concomitant removal of the decay products is likely to be unsustainable in most cases, as it will lead to increases in solute concentration or total volume. Though largely chemistry-specific, removal would require targeted separation processes, which are likely to be complex, energyintensive, and costly for concentrated multicomponent solutions, unless active species are intentionally designed to be easily separable from their decay products (e.g., if decay products are gases or easily precipitable). Recovered decomposition products could potentially be regenerated or repurposed, either for fresh electrolyte or as feedstock for other chemical processes, though the technical and economic feasibility of such strategies will again depend on the underlying chemistry. These complications should be factored into techno-economic assessments; although inexpensive active species may reduce upfront capital costs, operating and maintenance costs may ultimately challenge the viability of such systems [34].

Infinite-lifetime species experience minimal degradation and primarily lose capacity via crossover, which allows for a range of capacity recovery strategies [14]. In general, these redox couples 
consist of inorganic materials that are ideally low-cost, abundant, and soluble in aqueous electrolytes, often in the form of redox-active salts with the cation (e.g., Fe, Cr, Zn) [39,40], anion (e.g., Br, I, FeCN) [41,42], or in some cases both [43], storing charge. The stability of these species usually translates to a non-destructive crossover scenario, meaning they are stable in the chemical and electrochemical environment of both their original half-cell as well as the opposing half-cell. Thus, these chemistries can often be employed with the spectator strategy, where the electrolytes are mixed (i.e., contain both active species) to make the chemistry pseudo-symmetric and enable electrolyte rebalancing [14]. However, the spectator strategy decreases energy density and increases electrolyte cost by reducing the active species solubility and adding inactive chemicals, respectively, but if employed by suitable chemistries for stationary applications, these drawbacks may not be critical. An alternative approach to preventing capacity fade due to crossover is the use of a perfectly-selective membrane, such as a non-porous single-ion conductor (e.g., a ceramic). This strategy has received limited attention in the RFB field as experimental campaigns have been hampered by the cost, robustness, and increased resistance of available ceramics, as compared to polymeric membranes, all of which are anticipated to limit cell performance and system cost [4448]. Note that both the spectator and perfect separation strategies are also viable approaches for finite-lifetime chemistries as well, but do not address active species degradation (unless the degradation primarily results from crossover), which limits their value to these systems.

Here, we use a simple levelized cost of storage (LCOS) model to evaluate the techno-economic benefits and limitations of low-cost, asymmetric chemistries with active species of finite and infinite lifetimes. Previously, we developed an LCOS model for VRFBs to assess the value of capacity recovery, and used the framework to explore practical operating considerations, such as sizing, rebalancing schedule, and electrolyte leasing [49]. While LCOS analyses consider the lifetime costs of the system for the optimal long-term solution, short-term metrics like the capital cost are also important in evaluating considerations around project investment and financing. Indeed, capital cost targets are a key metric cited when contemplating the economic viability of different energy storage solutions [50,51]. Recognizing the need for RFBs with low capital costs, we extend our LCOS model to explore the methods and associated costs for capacity-loss remediation for asymmetric chemistries using active species of finite and infinite lifetimes. For the former, we explore the logistics and costs of the active-species replacement process. For the latter, we explore the spectator strategy, using iron-chromium as a case study, as well as the use of zero- 
crossover membranes as capacity remediation and elimination techniques, respectively. These systems are compared to the VRFB system, the incumbent solution (i.e., an RFB with higher capital costs and the ability to recover capacity at low costs) to determine the conditions under which the reduced upfront cost of less expensive, asymmetric chemistries offsets the more complex and, in some cases, more expensive maintenance required to recover capacity losses.

\section{Methods}

The methodology for this work is informed by the economic and physical models developed in Rodby et al. to assess the LCOS of VRFBs [49], with key modifications to the operating and maintenance costs based on the chemistries considered. As such, repetitive details are omitted from the main text but can be found in the Supporting Information (SI). In brief, we employ the following equation for $\operatorname{LCOS}\left(\$ \mathrm{MWh}^{-1}\right)$, defined generally as the ratio of the discounted costs to the discounted energy stored over a project lifetime:

$$
\text { LCOS }=\frac{\text { Discounted sum of costs over lifetime }}{\text { Discounted sum of energy stored over lifetime }}=\frac{\sum_{t=0}^{n} \frac{I_{\mathrm{t}}+L_{\mathrm{t}}+T_{\mathrm{t}}}{\left(1+r_{\mathrm{y}}\right)^{t}}+\sum_{t=0}^{k} \frac{O M_{\mathrm{t}}+C_{\mathrm{t}}}{\left(1+r_{\mathrm{d}}\right)^{t}}}{\sum_{t=0}^{k} \frac{E_{\mathrm{t}}}{\left(1+r_{\mathrm{d}}\right)^{t}}}
$$

where $I_{\mathrm{t}}(\$)$ is the investment expenditures, $L_{\mathrm{t}}(\$)$ and $T_{\mathrm{t}}(\$)$ are the loans and the taxes on those expenditures, respectively, $O M_{\mathrm{t}}(\$)$ is the operating and maintenance costs, $C_{\mathrm{t}}(\$)$ is the charging costs, and $E_{\mathrm{t}}(\mathrm{MWh})$ is the energy stored. These terms are tracked and summed across time $(t)$, which, depending on the term, is either on a yearly $\left(t \in\left\{\mathbb{Z}^{+} \cup[1, n]\right\}\right)$ or daily $\left(t \in\left\{\mathbb{Z}^{+} \cup[1, k]\right\}\right)$ basis, where $n$ and $k=365 n$ are the number of years and days of battery operation, respectively. The summed costs are discounted with a periodic rate, $r$, which is also applied yearly $\left(r_{\mathrm{y}}\right)$ or daily $\left(r_{\mathrm{d}}\right)$, depending on the cost period. Capacity loss is encompassed in the dynamic $E_{\mathrm{t}}$ term, while the costs to remediate capacity loss are captured in the $O M_{\mathrm{t}}$ and $C_{\mathrm{t}}$ terms. The full set of equations used to calculate the terms in Equation 1, as well as the inputs used for various parameters, are provided in Section S1 of the SI. This approach for modeling LCOS has been used before to assess energy-storage technologies, and we draw input values from those published reports [52,53].

The dynamic capacity model, which incorporates fade and recovery, is similar to that used in our earlier work [49], although here it is presented in a more generalized fashion that we subsequently 
adapt for each chemistry. We assume linear overall capacity fade, which is the sum of a constant rate of crossover losses ( $r_{\mathrm{CO}}$, in units of \% capacity loss per cycle), which can be remediated by rebalancing, and a constant rate of electrolyte decay losses ( $r_{\mathrm{ED}}$, also in units of \% capacity loss per cycle), which must be remediated using alternate servicing methods. We encompass all noncrossover losses in the electrolyte decay rate, which refers to side reactions and/or active species decay (the latter only applying to finite-lifetime chemistries). We elect to ignore any nonelectrolyte losses, such as membrane fouling or electrode decay, because these components generally degrade on timescales longer than those anticipated for electrolyte crossover and decay (i.e., require replacement every five to ten years [7,54]) and their degradation is assumed to be independent of the symmetry or lifetime of the chemistry, the focus of this work. The capacity accessed in a given cycle is equal to the product of the nominal battery size and $f_{\text {cap }}$, the fraction of original capacity accessible at that time. This fraction changes as the battery experiences electrolyte decay/crossover and subsequent remediation:

$$
f_{\text {cap }}=100 \%-\left[r_{E D} * n_{c y c}^{S}(t)\right]-\left[r_{C O} * n_{c y c}^{R}(t)\right]
$$

where $n_{\text {cyc }}^{\mathrm{R}}$ and $n_{\mathrm{cyc}}^{\mathrm{S}}$ are the number of cycles passed since the last rebalancing event (i.e., $t=R$ ) and the number of cycles passed since the last servicing event (i.e., $t=S$ ), respectively. These counters increase each cycle and reset once rebalancing or servicing occurs and capacity is regained. These terms are further defined in Equation 3. We note that servicing also resets the rebalancing counter, as we assume servicing achieves total capacity recovery.

$$
n_{\mathrm{cyc}}^{R / S}(t)=\left\{\begin{array}{l}
0, t=0 \text { or upon rebalancing }(\mathrm{R}) \text { or servicing }(\mathrm{S}) \\
n_{\mathrm{cyc}}^{\mathrm{R} / \mathrm{S}}(t-1)+1, t>0 \text { and not rebalancing }(\mathrm{R}) \text { or servicing }(\mathrm{S})
\end{array}\right.
$$

To determine when to service or rebalance the system, we define a lower capacity limit (cap lim); ) once the accessible capacity declines to the $c_{\text {lim }}$, capacity remediation is performed. In the case of symmetric and pseudo-symmetric chemistries, rebalancing will occur, which regains the capacity lost to crossover but not that lost to electrolyte decay. This process repeats until the total accessible capacity upon rebalancing has decayed to the $\operatorname{cap}_{\lim }$ (i.e., $\operatorname{cap}_{\lim } \leq 100 \%-r_{\mathrm{ED}} *$ $n_{\text {cyc }}^{\mathrm{S}}(t)$ ), at which point electrolyte servicing is performed. Where rebalancing is not feasible (i.e., asymmetric chemistries), rebalancing is not employed and instead a servicing event occurs each time the accessible capacity decays to the $\operatorname{cap}_{\text {lim. }}$. This iterative capacity fade and recovery process is illustrated in Figure 1, which exemplifies a simulation of the capacities of a generic symmetric 
and asymmetric RFB as a function of time. The nominal capacity rating is maintained via a combination of the choice of $c^{a p}$ lim and oversizing of the capacity. Under a given scenario, the tradeoff between the increase in upfront cost to oversizing (i.e., higher oversizing factor, $O F$ ) and the ability to remediate capacity losses less frequently (i.e., lower $c a p_{\text {lim }}$ ) is optimized to find the combination of $c a p_{\mathrm{lim}}$ and $O F$ that minimizes the LCOS. The optimal $c a p_{\mathrm{lim}} / O F$ balance changes as the conditions or chemistries vary; Figure 1 exemplifies how symmetric chemistries would likely have higher optimal cap $_{\text {lim }}$ values, as compared to asymmetric systems, because their ability to regain capacity loss with low-cost maintenance makes more frequent remediation preferable (i.e., results in a lower LCOS) to more significant capacity oversizing.

The costs of performing electrolyte maintenance are chemistry-specific and can be generally summarized as: (1) the cost of electricity to perform rebalancing to account for the energetic losses of crossover and self-discharge, which is only applicable to symmetric and pseudo-symmetric chemistries, and (2) the cost to perform servicing, which requires "oxidative maintenance" (e.g., reductant chemicals, for VRFB, or a rebalancing cell, for iron-chromium) for infinite-lifetime asymmetric chemistries or "decay maintenance" (i.e., separation and replacement or recovery of the decayed species, or total electrolyte replacement) for finite-lifetime asymmetric chemistries. The specific methods for modeling these costs are explained in greater qualitative detail in the Results \& Discussion and in greater quantitative detail in Section S1 of the SI. Input values for relevant parameters that are used for the various chemistries contemplated here are summarized in Table 1.

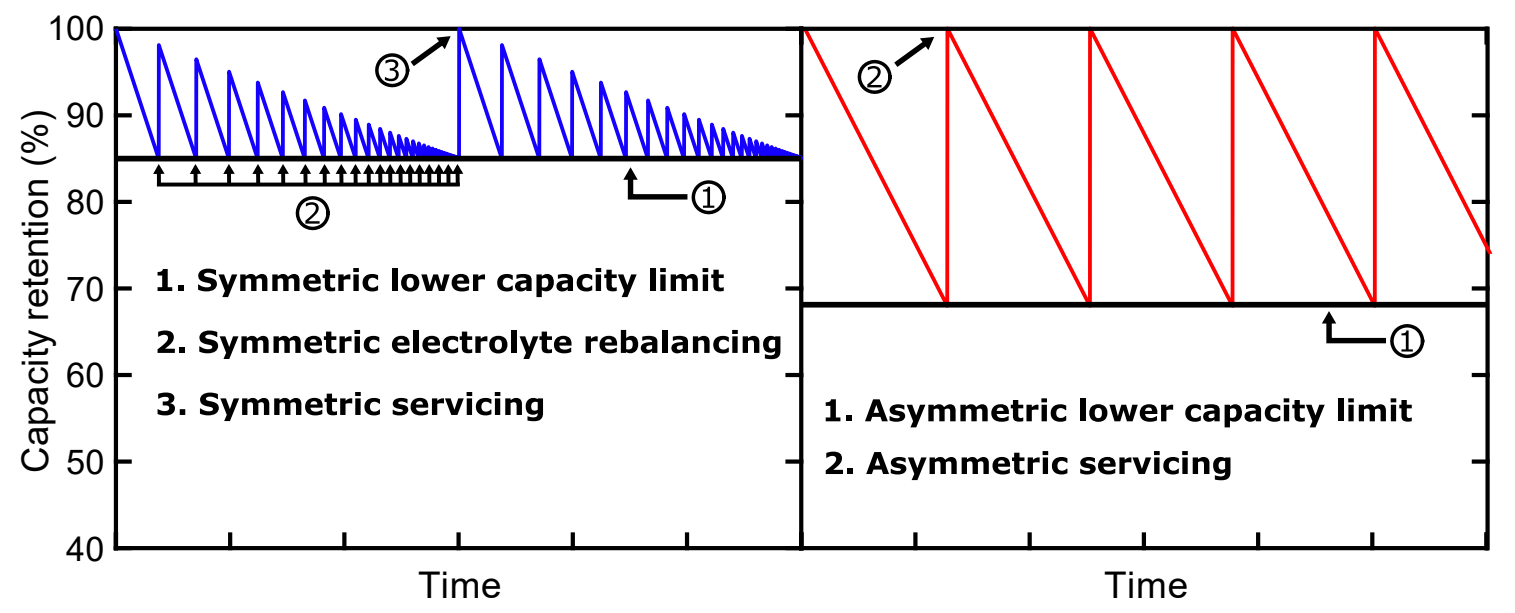

Figure 1 - Example of the simulated capacity retention for generic symmetric (left, blue; e.g., VRFB) and asymmetric (right, red) RFB chemistries (for illustrative purposes). 
Table 1 - Symbols, names, assumptions, values, and sources for the chemistry-specific model parameters. Values with asterisks $(*)$ are baseline values but are subsequently varied in sensitivity analyses. For the "generic infinite-lifetime chemistry and/or Fe-Cr" column, the values given for each parameter apply to both cases except for the asterisked variables, of which the baseline values correspond to the Fe-Cr case but are varied for the generic case (see Figure 3).

\begin{tabular}{|c|c|c|c|c|c|}
\hline \multirow[t]{2}{*}{ Symbol } & \multirow[t]{2}{*}{ Name } & \multirow[t]{2}{*}{ Assumptions } & \multicolumn{3}{|c|}{ Values and Sources } \\
\hline & & & VRFB & $\begin{array}{l}\text { Generic infinite- } \\
\text { lifetime chemistry } \\
\text { and/or } \mathrm{Fe}-\mathrm{Cr}\end{array}$ & $\begin{array}{c}\text { Generic } \\
\text { finite-lifetime } \\
\text { chemistry }\end{array}$ \\
\hline$O$ & $\begin{array}{l}\text { Operational } \\
\text { servicing fee }\end{array}$ & $\begin{array}{c}\text { Electrolyte service } \\
\text { fee (labor, transport, } \\
\text { and other bulk costs; } \\
\text { excludes electrolyte } \\
\text { costs) }\end{array}$ & $\begin{array}{l}0 \$ \mathrm{kWh}^{-1} \text { per visit } \\
(\text { see Section } 3.1)\end{array}$ & $\begin{array}{l}\text { N.A. } \\
\text { (see SI Section } \\
\text { S1.2) }\end{array}$ & $\begin{array}{c}\text { 4-20 } \$ \mathrm{kWh}^{-1} \text { per } \\
\text { visit } \\
\text { (see Section 3.1) }\end{array}$ \\
\hline$\varepsilon_{\mathrm{E}}$ & $\begin{array}{l}\text { Roundtrip } \\
\text { system cycle } \\
\text { energy } \\
\text { efficiency }\end{array}$ & $\begin{array}{l}\text { Product of voltaic, } \\
\text { coulombic, and } \\
\text { system efficiencies }\end{array}$ & $75 \%$ [55] & $75 \%[55]$ & $75 \%[55]$ \\
\hline$r_{\mathrm{CO}}$ & $\begin{array}{l}\text { Crossover } \\
\text { fade rate }\end{array}$ & $\begin{array}{l}\text { Contribution of fade } \\
\text { recovered with } \\
\text { rebalancing }\end{array}$ & $\begin{array}{l}0.387 \% \text { capacity } \\
\text { loss per cycle }[49]\end{array}$ & $\begin{array}{l}0.3 \% \text { capacity loss per } \\
\text { cycle }[24]\end{array}$ & $\begin{array}{l}0 \% \text { capacity loss } \\
\text { per cycle } \\
\text { (see Section } 3.1 \text { ) }\end{array}$ \\
\hline$r_{\mathrm{ED}}$ & $\begin{array}{l}\text { Electrolyte } \\
\text { decay rate }\end{array}$ & $\begin{array}{l}\text { Contribution of fade } \\
\text { requiring servicing to } \\
\text { remediate }\end{array}$ & $\begin{array}{l}0.055 \% \text { capacity } \\
\text { loss per cycle }[49]\end{array}$ & $\begin{array}{c}0 \% \text { capacity loss per } \\
\text { cycle (see SI Section } \\
\text { S1.2) }\end{array}$ & $\begin{array}{c}* 0.1 \% \text { capacity } \\
\text { loss per cycle } \\
(\text { see Section } 3.1)\end{array}$ \\
\hline$U$ & $\begin{array}{l}\text { Open circuit } \\
\text { voltage }\end{array}$ & $\begin{array}{l}\text { At } 50 \% \text { SOC and } \\
\text { relevant operating } \\
\text { conditions }\end{array}$ & $1.4 \mathrm{~V}$ [55] & * $0.98 \mathrm{~V}[56]$ & $1.5 \mathrm{~V}$ [55] \\
\hline$M W_{\text {active }}$ & $\begin{array}{c}\text { Equivalent } \\
\text { weight of } \\
\text { active species }\end{array}$ & - & $\begin{array}{l}51 \mathrm{~g} \mathrm{~mol}^{-1} \\
(\text { vanadium })\end{array}$ & $\begin{array}{l}* 52 \mathrm{~g} \mathrm{~mol}^{-1} \\
\text { (chromium) }\end{array}$ & $150 \mathrm{~g} \mathrm{~mol}^{-1}[55]$ \\
\hline $\operatorname{conc}_{\text {active }}$ & $\begin{array}{l}\text { Concentration } \\
\text { of active } \\
\text { species }\end{array}$ & $\begin{array}{l}\text { Concentration near } \\
\text { general aqueous } \\
\text { solubility limit of } 1.5 \\
\text { M, } 1 \mathrm{M} \text { for spectator } \\
\text { strategy cases }\end{array}$ & $1.5 \mathrm{M}$ & $1 \mathrm{M}$ [57] & $1.5 \mathrm{M}$ \\
\hline$c_{\text {active }}$ & $\begin{array}{l}\text { Cost of active } \\
\text { material }\end{array}$ & 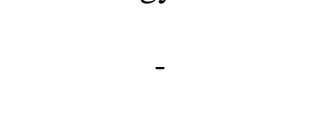 & $\begin{array}{l}30.14 \$ \mathrm{~kg}^{-1} \mathrm{~V} \\
{[25](\text { see SI }} \\
\text { Section S2.3) }\end{array}$ & $\begin{array}{c}2.29 \$ \mathrm{~kg}^{-1} \mathrm{Cr} \\
{[58,59]}\end{array}$ & $\begin{array}{c}* 3.50 \$ \mathrm{~kg}^{-1} \\
{[32,55,60]}\end{array}$ \\
\hline$C_{\text {electrolyte }}$ & $\begin{array}{l}\text { Total cost of } \\
\text { electrolyte }\end{array}$ & $\begin{array}{c}\text { Cost per energy } \\
\text { throughput, before } \\
\text { oversizing }(\mathrm{OF}=1) \text {. } \\
\text { See SI Section S2.2 }\end{array}$ & $122 \$ \mathrm{kWh}^{-1}$ & $* 23 \$ \mathrm{kWh}^{-1}$ & $* 50 \$ \mathrm{kWh}^{-1}$ \\
\hline$c_{\mathrm{a}}$ & $\begin{array}{l}\text { Areal cost of } \\
\text { reactor }\end{array}$ & $\begin{array}{l}\text { Estimated from } \\
\text { existing RFB techno- } \\
\text { economic analyses, } \\
\text { see SI Section S2.2 }\end{array}$ & $\begin{array}{l}450 \$ \mathrm{~m}^{-2} \\
158 \$ \mathrm{~kW}^{-1} \\
{[54,55,61]}\end{array}$ & $\begin{array}{l}450 \$ \mathrm{~m}^{-2} \\
323 \$ \mathrm{~kW}^{-1} \\
{[54,55,61]}\end{array}$ & $\begin{array}{c}* 450 \$ \mathrm{~m}^{-2} \\
138 \$ \mathrm{~kW}^{-1} \\
{[54,55,61]}\end{array}$ \\
\hline
\end{tabular}




\section{Results and discussion}

We apply our LCOS model to the two asymmetric chemistry classes - those with active species of either finite or infinite lifetimes - and compare these results to a VRFB baseline to evaluate their ability to compete with the state-of-the-art. Regarding finite-lifetime chemistries, we model different options for active-species replacement and explore the feasibility of each, while also estimating the sensitivity of LCOS to electrolyte decay rate, electrolyte cost, and reactor cost for each remediation scheme. For infinite-lifetime chemistries, we consider two methods for addressing crossover losses: 1) remediation of crossover by applying the spectator strategy to make the chemistry pseudo-symmetric and allow for rebalancing, or 2) elimination of crossover altogether via use of a perfectly selective separator. In examining the spectator strategy, we focus on the ability of a chemistry to competitively employ this scheme through calculation of the electrolyte cost, and use iron-chromium as a case study. In examining the perfectly selective separator case, we determine the bounds of separator cost, cell potential, and cell resistance needed to approach viability.

\subsection{Remediating capacity loss for asymmetric chemistries with active species of finite lifetime: active-species replacement}

RFB chemistries with finite lifetimes inevitably require periodic active-species replacement. To our knowledge, the logistics of such processes have yet to be considered in the published literature but likely possess technical and economic challenges specific to the underlying chemistry. In these finite-lifetime systems, capacity fade is due to a combination of crossover and active species decay, although, for most embodiments to date, active species decay rates are generally one or more orders of magnitude greater than the rates of loss due to crossover [30]. We propose two potential options for capacity remediation for such systems, each employed periodically: (1) separation and removal of the "contaminants" (i.e., species that have decayed or crossed over), followed by either (1a) replacement with fresh active species or (1b) recovery and reuse of the active species from these contaminants (which may require methods to reverse decay), or (2) total replacement of the electrolytes. Targeted removal of contaminants eliminates the waste of replacing non-decayed electrolyte and may even allow for reuse of the recovered species, but the selectivity, energy 
requirements, and cost of chemistry-specific separation processes are unknown and may be prohibitive. Conversely, one could eliminate the need for any separation processes, at least on-site, by replacing the entire electrolyte upon reaching a capacity loss threshold (i.e., cap $_{\text {lim }}$ ), but this requires the exchange of large volumes and potentially sacrifices a significant quantity of valuable material. For the first option, we model only the separate/recover/reuse scenario (1b), as the separate/replace scheme (1a) lies between the lower bound of full reuse and the upper bound of total electrolyte replacement options in terms of resources required. Again, we note that simple addition of more active species or electrolyte without concomitant removal of contaminants or contaminated electrolyte is likely to be an unsustainable solution in most cases, as it will lead to increases in solute concentration or total volume, respectively.

These two remediation schemes are modeled differently, though both are fairly simple to represent. Total electrolyte replacement cost is intuitively modeled as the product of the electrolyte cost $\left(C_{\text {electrolyte }} \$ \mathrm{kWh}^{-1}\right)$ and the nominal capacity rating of the battery, plus an operational servicing fee. In this case, the fee should cover the labor to execute the replacement, the cost to transport electrolyte to and from the battery site, and perhaps the post-processing or disposal of the spent electrolyte. We estimate the costs for the labor and transport are $\sim 4 \$ \mathrm{kWh}^{-1}$, so we use this as a lower bound for the servicing fees used with the finite-lifetime cases (see SI Section S1.3 for details). Conversely, the separate/recover/reuse scenario is difficult to rigorously model, as there is chemistry-specificity regarding the exact methods and, by extension, associated costs needed to separate out decayed and crossed-over contaminants, reverse any decay, and finally reintroduce these species to their original half-cell. Accordingly, we elect to encompass all of these material and energy costs, in addition to the cost of the labor required to execute these actions, in the bulk operational servicing fee term. By varying the magnitude of the service fee (here, we show results using 4 and $20 \$ \mathrm{kWh}^{-1}$ ), it is possible to estimate what additional servicing costs are allowable if the RFB chemistry is to be cost-competitive with the VRFB, on a LCOS basis. To further facilitate the modeling of these chemistries, we set the $r_{\mathrm{CO}}$ (the capacity fade rate that is recoverable upon rebalancing) to $0 \%$ per cycle, encompassing all fade in the $r_{\mathrm{ED}}$ term, as all fade experienced in these asymmetric chemistries must be recovered via servicing (i.e., rebalancing to remediate crossover losses is not an option). Thus, crossover is treated as a mode of electrolyte decay, because it requires the same general remediation mechanisms as active species decay (i.e., options 1 and 2, explained above). We note that crossover complicates the chemistry-specific separations 
needed by adding more species to separate on top of those that have decayed, particularly because the fate of crossed-over species (i.e., whether they stay intact or decay to any number of products) could be uncertain or variable [62]. Finally, as discussed in the Introduction, we assume these finite-lifetime species are organic compounds, with an average equivalent weight of 150 grams per mole, in aqueous electrolytes (we also assume that, in the case of two electron transfer, both transfer events occur at the same electrode potential) [55]. Quantitative representations of the chemistry-specific servicing costs (which includes both the servicing fee as well as other chemical costs, which are treated separately) can be found in Section S1.2 of the SI.

In addition to the operational service fee, the achievable lower bounds of electrolyte decay rate and electrolyte cost for finite-lifetime chemistries remain open questions and are the focus of active fundamental and applied research. To date, at-scale demonstrations of finite-lifetime chemistries in RFBs have been limited to a few start-up companies [63-67], and details on their specific redox chemistries, system configurations, performance abilities, and operational and maintenance approaches are not reported. Consequently, we perform sensitivity analyses on electrolyte cost and decay rate, along with reactor cost, to determine cost and performance targets. Figure 2 below shows the LCOS sensitivity as a function of these three variables for the two remediation schemes (separate/recover/reuse in green and total electrolyte replacement in red) for an asymmetric, finitelifetime chemistry. Values for VRFBs are provided for comparison (plotted in blue), which are treated as constant base cases because they have a relatively developed market and established body of research such that there is greater certainty around the present techno-economic parameter values. The VRFB case assumes a service fee of $0 \$ \mathrm{kWh}^{-1}$, as it must only encompass the labor of adding the chemical reductant, which was determined to be negligible (see SI Section S1.3), while two higher service fees ( 4 and $20 \$ \mathrm{kWh}^{-1}$ ) are used for the asymmetric cases. These different operational service fees are represented by varying line styles. There are two immediate insights gained from Figure 2: (1) LCOS is highly sensitive to electrolyte decay rate and electrolyte cost, and (2) the separate/recover/reuse scheme appears more likely to be competitive with VRFBs than the total replacement scheme. Indeed, at a service fee of $4 \$ \mathrm{kWh}^{-1}$, total electrolyte replacement requires very low decay rates $(\leq 0.02 \%$ capacity loss per day at the baseline electrolyte cost of $\sim 50$ $\left.\$ \mathrm{kWh}^{-1}\right)$ and/or electrolyte costs $\left(\leq 13 \$ \mathrm{kWh}^{-1}\right.$ at the baseline decay rate of $0.1 \%$ capacity loss per day), or some optimal combination between these baselines and targets for both parameters, to achieve a lower LCOS than a VRFB. Whereas, even with a higher service fee of $20 \$ \mathrm{kWh}^{-1}$, the 
separate/recover/reuse scheme enables more lenient targets for the decay rate $(\leq 0.06 \%$ capacity loss per day at the baseline electrolyte cost of $\sim 50 \$ \mathrm{kWh}^{-1}$ ) and the electrolyte cost $\left(\leq 30 \$ \mathrm{kWh}^{-1}\right.$ at the baseline decay rate of $0.1 \%$ capacity loss per day). However, these cost and performance targets are highly dependent on the service fee, particularly for the separate/recover/reuse scheme.

To contextualize these electrolyte cost targets, we can look to the limited techno-economic studies on aqueous organic electrolytes (note: all studies assume an average cell voltage of 1.5 V). Darling et al. estimated the electrolyte cost for an aqueous organic RFB to be $\sim 235 \$ \mathrm{kWh}^{-1}$ in 2014 , and between 45 and $90 \$ \mathrm{kWh}^{-1}$ in the "future" [55]. The 2018 work by Dieterich et al. modeled the production cost of AQDS ( 157 grams per mole electron, assuming a two-electron transfer), a well-known finite-lifetime active species for RFBs that is relatively easy and low-cost to manufacture [23,68], and estimated the total electrolyte cost for an AQDS chemistry (assuming the cost of the negative and positive electrolytes are approximately equal) to be 50 and $65 \$ \mathrm{kWh}^{-}$ ${ }^{1}$ at production scales $\sim 100$ and $\sim 200$ MWh of flow battery capacity deployed per year, respectively [32]. Based on their estimates of materials costs alone, it is difficult to envision reducing electrolyte costs below $30 \$ \mathrm{kWh}^{-1}$ while utilizing existing production methods (regardless of production scale). Furthermore, a recent study by Gregory et al. estimates that reducing the electrolyte price of an aqueous RFB system using AQDS on the negative side or a ferrocyanide-based positive electrolyte to our baseline electrolyte cost of $25 \$ \mathrm{kWh}^{-1}$ per side (i.e., $50 \$ \mathrm{kWh}^{-1}$ overall) would require a production scale equivalent to producing $10 \mathrm{GWh}$ of flow batteries per year [60]. Currently, there only $\sim 100 \mathrm{MWh}$ of RFBs deployed globally, with another $\sim 1$ GWh contracted, announced, or under construction [69]. These studies clearly demonstrate that low-cost (i.e., $\leq 50$ $\$ \mathrm{kWh}^{-1}$ ) electrolytes for finite-lifetime chemistries will require one or more of the following factors: the use of previously unstudied active molecules, development of new production pathways for existing active molecules (e.g., AQDS), internal production of the active molecules by the RFB company (to minimize markups by suppliers), and/or drastic increases to production scale (either by growth of the RFB market utilizing these chemistries and/or other markets for these active species). Therefore, the more promising pathways to viable asymmetric chemistries with finite lifetimes are those that can enable low service fees or low decay rates.

With respect to electrolyte decay rates, those reported in the literature range five orders of magnitude (from as low as order 0.001 to as high as order 10, in units of \% capacity loss per day), 
which challenges a feasibility judgement on the decay-rate baseline of $0.1 \%$ capacity loss per day $[30,37,38]$. This variability can be attributed to differences in the choices of active species, experimental apparatus, testing protocols, and other experimental conditions. Further, the protocols and the conditions used to measure these decay rates may be less aggressive than those of a deployed system, potentially making these conservative estimates. That said, several publications have reported active-species stability in the desired range of $\leq 0.1 \%$ capacity loss per day $[30,37,38,70,71]$, including many quinone-derivatives. In working to reduce these key variables, note that electrolyte price and decay rate may not be independent, as functionalization of organic molecules often improves stability [30,72] and, likely, simultaneously complicates the manufacturing process and thus adds to the chemical cost. Relative to those two variables, reactor cost has a lesser effect on LCOS, though it is important to consider as organic molecules are generally larger than their aqueous supporting salts, providing the opportunity to leverage sizeexclusion membranes as opposed to more expensive ion-exchange membranes [33]. There is also the potential to employ lower-cost membranes ill-suited for VRFBs, either via the use of electrolytes with milder $p H[37,70]$ or a less oxidizing active species [9].

Based on our evaluations of the feasibility of achieving the relevant targets for electrolyte cost and decay rate, the separate/recover/reuse remediation process appears capable of making asymmetric chemistries of finite lifetimes competitive with VRFBs if the service fees to employ it can be kept sufficiently low. The $20 \$ \mathrm{kWh}^{-1}$ service fee already sets seemingly difficult targets; for example, an electrolyte cost of $30 \$ \mathrm{kWh}^{-1}$ seems infeasible with our current solutions, even assuming the possibility of vast scale-up, as previously discussed. From these observations, we propose that the costs to separate/recover/reuse should be limited to $\leq 10 \$ \mathrm{kWh}^{-1}$ to allow for viability at the expected lower limits for electrolyte cost and decay rate. At this juncture, it is difficult to assess the feasibility of this target, due to the absence of discussion or study of these methods in the open literature. A notable exception is the work of Goulet et al., which explored decay reversibility for an aqueous chemistry with a finite-lifetime species on the negative side (i.e., a quinone derivative) [36]. The authors were able to reverse $70 \%$ of the decay, which had already been mitigated to 0.14 $\%$ per day by limiting the state of charge, via aeration of the electrolyte. They estimated that the modifications to RFB operation needed to facilitate this capacity loss reduction/remediation would add $\sim 20 \$ \mathrm{kWh}^{-1}$ to the capital cost, which corresponds to an annual operating and maintenance cost of just over $2 \$ \mathrm{kWh}^{-1}$ per year if calculated assuming a 20 year lifetime and $8 \%$ discount rate 
[73]; while this is within our desired range, the remaining $30 \%$ of the decayed species that cannot be rejuvenated via aeration alone would eventually require separations.

Three complicating features of this system to consider regarding separations are (1) the high overall electrolyte concentrations, (2) the need to keep the main stream of electrolyte (i.e., what remains after separating out the decayed species) almost entirely uncontaminated from the separations process and the further desire to recover the decayed species intact as well for reuse in the system, and (3) the likely similar characteristics of the decayed species being targeted for separations and the active species that must remain in the electrolyte. Methods for separating organics via exploitation of differences in the physical, chemical, and/or electrochemical properties exist and can even separate similar compounds (e.g., isomers) [74,75]. It seems reasonable to assume that expertise in separating decay product lies within the process industry given the requirements to create products of sufficient purity. Consequently, chemical manufacturers may be uniquely positioned to design new redox active compounds with decay reversal or recovery as a key design parameter, or else offer technical solutions for separation of pristine species from decay products either on-site or at a centralized facility. Next, we consider remediation techniques for infinite-lifetime species. We note that while separations processes could be used for crossover remediation in these cases as well - and there are, in fact, relatively developed and low-cost methods for separating mono- and multi-valent ions from multicomponent mixtures (e.g., wastewater treatment) [76] - the other techniques available for these chemistries, discussed below, are anticipated to be economically preferable to total electrolyte replacement or complicated separations. 

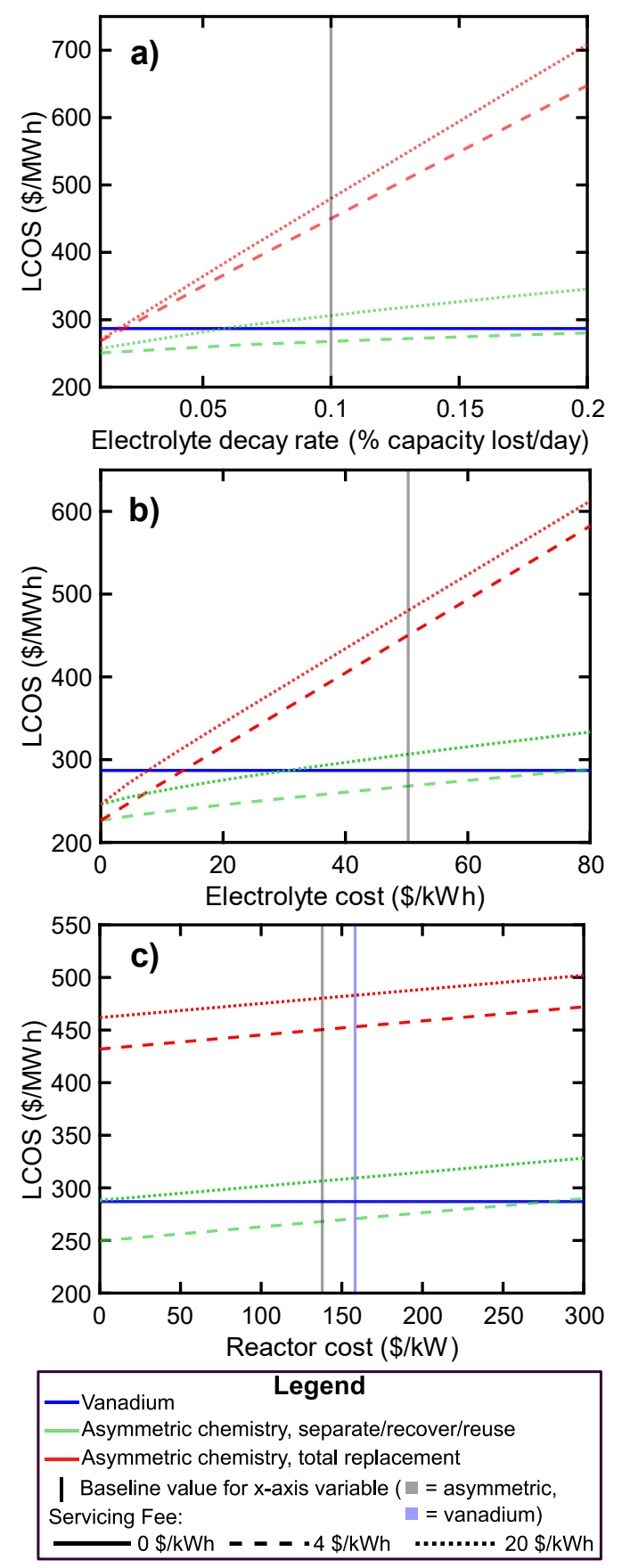

Figure 2 - LCOS as a function of electrolyte decay rate (a, top), electrolyte cost (b, middle), and reactor cost (c, bottom) for a generic, asymmetric chemistry employing the separation/recovery/reuse remediation method (green lines) or total electrolyte replacement remediation method (red lines). These are compared against baselines for a VRFB (blue lines), which do not change with the $\mathrm{x}$-axis variables. The vertical lines represent the baseline value of each $\mathrm{x}$-axis variable for the asymmetric case (grey) and the vanadium case (blue) (note that vanadium does not decay and its electrolyte cost, $\sim 122 \$ \mathrm{kWh}^{-1}$, exceeds the $\mathrm{x}$-axis scale in $2 \mathrm{~b}$, thus the vanadium $\mathrm{x}$-axis baseline is only visible in $2 \mathrm{c}$ ). The line styles correspond to varying operational service fees. 


\subsection{Remediating capacity loss for asymmetric chemistries with active species of infinite lifetime: the spectator strategy}

Crossover - driven by electroosmotic drag and gradients of concentration, potential, and/or pressure across the half-cells - is a primary cause of capacity loss for asymmetric RFB chemistries with active species of infinite lifetimes. However, the stability of these active species in their home and opposing cell environments enables use of the spectator strategy, where both active species are dissolved in each half-cell electrolyte. A mixed electrolyte is typically prepared with equal concentrations of active species in their discharged forms and used in both reservoirs. During operation, the active species for the positive half-cell reaction serves as the charge storage species on the positive side of the cell and as a spectator on the negative side of the cell. The opposite is true for the active species for the negative half-cell reaction. This transforms asymmetric chemistries into pseudo-symmetric chemistries and allows for utilization of the same VRFB rebalancing methods $[12,49,77-80]$ to remediate losses due to crossover. Further, crossover is actually mitigated by the spectator methodology itself [14,81], as diffusive fluxes between the two electrolytes that drive crossover are also significantly decreased with this strategy [62].

As mentioned before, implementation of this strategy requires that both active species are chemically and electrochemically stable in the opposing half-cell, but there are also important techno-economic considerations. The spectator strategy typically decreases energy density and increases electrolyte cost, limiting the chemistries to which this approach can be applied costeffectively. The addition of the spectator species lowers the solubility of the active species [14], limiting the energy density, as well as doubles the active material required for the same energy output, increasing electrolyte costs. Lower energy densities are arguably less concerning for stationary energy storage applications where the size and mass constraints for the battery are more lenient as compared to mobile ones, but the increased electrolyte cost could be prohibitive for grid applications where lower cost solutions (e.g., fossil fuels or cheaper battery chemistries/technologies) are readily available. At the very least, the savings from employing a low-cost asymmetric material set may be lost if the spectator strategy increases the energy costs to the point they exceed that of the incumbent VRFB chemistry. Thus, we can calculate the total electrolyte cost for a spectator chemistry as a function of three key variables - active species costs, active species equivalent weight, and cell potential - to estimate the available design space for 
these chemistries to be competitive the VRFB (Figure 3). Other variables that affect electrolyte cost - such as accessible depth of discharge, cost of solvent, solubility, etc. - are generally more consistent across aqueous chemistries, as compared to these three highly chemistry-dependent variables [55]. We vary equivalent weight and cell potential within the bounds typically seen in RFB chemistries (50-150 grams per mole and 1.0-1.6 V, respectively [55]), and use a range of active species costs that would generally classify low-cost, high-abundance materials $\left(\leq 20 \$ \mathrm{~kg}^{-}\right.$ ${ }^{1}$ ). Across the range of values studied, the combination of the active species equivalent weight and chemical cost significantly impacts the final electrolyte cost and thus the economic viability, whereas cell potential has a less pronounced effect, particularly with increasing active species equivalent weight (though we note that cell potential also impacts the power costs, which is not accounted for in this simple electrolyte-cost comparison). We see the majority of the design space for these spectator strategy chemistries is competitive with the VRFB, and this space seems reasonable: many new chemistries being studied use abundant active materials, such as iron, zinc, sulfur, etc., all of which have been cited in RFB literature to cost $\leq 10 \$ \mathrm{~kg}^{-1}$ and have equivalent weights and cell voltages in the middle of these ranges [55,59]. However, using this strategy with larger active species ( 150 grams per mole), such as organics or ligand-modified transition metals, requires very low costs to be competitive with $\operatorname{VRFB}\left(\leq 5 \$ \mathrm{~kg}^{-1}\right)$. Several RFB chemistries leverage the spectator strategy $[82,83]$, with perhaps the most notable being iron-chromium $(\mathrm{Fe}-\mathrm{Cr})$. 


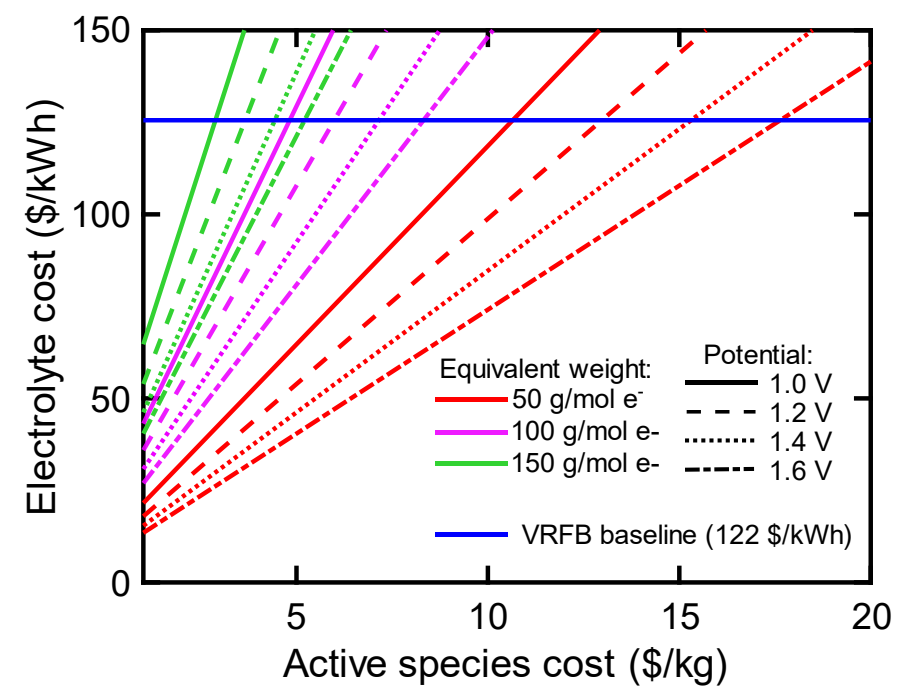

Figure 3 - Electrolyte cost (y-axis) as a function of active species cost (x-axis), active species equivalent weight (line colors), and cell potential (line styles) for chemistries utilizing the spectator strategy. For context, the baseline electrolyte cost of the VRFB (122 $\$ \mathrm{kWh}^{-1}$, assuming an equivalent weight of 51 grams per mole, active species cost of $\sim 30 \$ \mathrm{~kg}^{-1}$, and potential of $1.4 \mathrm{~V}$ ) is plotted as a blue solid line.

The pseudo-symmetric Fe-Cr RFB offers several benefits as compared to the VRFB. Use of the spectator method for the Fe-Cr chemistry has been shown to significantly reduce net crossover rates [84], which is important as iron and chromium ions are $\sim 20 \times$ more permeable than vanadium ions in Nafion membranes [85]. The chemistry uses charge-storage species of high crustal abundance, as iron is the most abundant element in the Earth (by mass) and there is nearly 1000x more chromium resources than vanadium [26]. These active materials are also low-cost: from late 2019 through early 2020, the price of ferrochromium was $\sim 2 \$ \mathrm{~kg}^{-1}$ of chromium content [58]. Further, ferrochromium contains forms of both active species, which can facilitate cost savings by minimizing waste and reducing the processing steps needed to generate to electrochemical grade electrolyte if employed in an Fe-Cr system utilizing spectator strategy [84]. However, the open circuit voltage of $\mathrm{Fe}-\mathrm{Cr}$ is $\sim 0.98 \mathrm{~V}$ at typical operating temperatures (i.e., $\sim 65^{\circ} \mathrm{C}$ ) [84] and the active species solubility in the spectator configuration are $~ 1 \mathrm{M}[56,81]$, limiting energy and power densities. Assuming a four-hour duration, we estimate the capital cost of the Fe-Cr RFB to be lower than that of the VRFB, at $\sim 211$ and $\sim 268 \$ \mathrm{kWh}^{-1}$ (including optimal oversizing to minimize LCOS, as explained previously), respectively, where the electrolyte costs of the $\mathrm{Fe}-\mathrm{Cr}$ are about a fifth of the VRFB electrolyte costs ( 23 and $\sim 122 \$ \mathrm{kWh}^{-1}$, respectively, not including oversizing) 
and the reactor costs of the Fe-Cr are about double that of the VRFB $\left(\sim 323\right.$ and $\sim 158 \$ \mathrm{~kW}^{-1}$, respectively). These numbers align with other techno-economic assessments of these systems $[7,24]$. Despite also facing capacity loss due to hydrogen evolution at a rate $\sim 20 \times$ that seen in VRFBs ( $\sim 1 \%$ vs $0.055 \%$ of capacity loss to hydrogen evolution per cycle) $[24,54,86]$, the $\mathrm{Fe}-\mathrm{Cr}$ system also shows improvement over VRFBs in terms of LCOS. We estimate the LCOS of Fe-Cr to be $\sim 260 \$ \mathrm{MWh}^{-1}$, a moderate reduction from the LCOS of the VRFB ( 290\$ $\left.\mathrm{MWh}^{-1}\right)$. Even artificially increasing the hydrogen evolution-induced capacity fade rate in the $\mathrm{Fe}-\mathrm{Cr}$ system to as much as $10 \%$ capacity loss per cycle does not raise the LCOS of the Fe-Cr system above $270 \$$ $\mathrm{MWh}^{-1}$. Modeling details used to derive these numbers can be found throughout the SI. The techno-economic promise for Fe-Cr is evident, however, the capital cost of the system still exceeds the Department of Energy target of $\leq 150 \$ \mathrm{kWh}^{-1}$ for viable grid storage [50,51]. Reductions in the power costs (i.e., beyond the chemistry choices probed in this work, perhaps by increasing the duration or using lower-cost reactor materials) are likely needed. There is, however, the potential for further cost reductions for the $\mathrm{Fe}-\mathrm{Cr}$ system with any significant improvements to performance. Most of the Fe-Cr research was executed in the 1970's and 1980's when NASA first introduced this chemistry as the first true RFB while exploring energy storage solutions for deep-space missions [87]. Research into the Fe-Cr system has been limited relative to that for VRFBs, and it is likely that many of the significant improvements to the VRFB system seen over the past 5-10 years can be applied to the Fe-Cr system to increase performance and reduce costs. Some of this has already been demonstrated; for example, recent studies have shown the benefits of advanced cell engineering and optimized electrolyte composition for the $\mathrm{Fe}-\mathrm{Cr}$ system $[39,57]$.

\subsection{Eliminating crossover with ceramic membranes}

Membranes with perfect selectivity for the desired charge-carrier species, such as non-porous, single ion-conducting (SIC) materials, could eliminate crossover losses experienced by stable RFB chemistries, obviating the need for symmetric and pseudo-symmetric electrolytes. Research into SIC membranes, mainly ceramics and ceramic-polymer composites, for RFBs has been limited, with most studies employing them for energy dense semi-solid/hybrid redox chemistries or 
systems utilizing two electrolytes of different $\mathrm{pH}[44-48,88]$. More extensive exploration has likely been hampered by the absence of broadly-available commercial materials, the lack of crossdisciplinary expertise between the fields, and the experimental challenges of integrating a ceramic into a contemporary flow-cell architecture. There is an inherent tradeoff between improving (i.e., increasing) selectivity and worsening (i.e., increasing) resistivity, and thus high selectivity typically results in large ohmic resistance; for example, Allcorn et al. measured a resistance of $\sim 90$ $\Omega-\mathrm{cm}^{2}$ for their $1.1 \mathrm{~mm}$ thick ceramic membrane (using a symmetric ferro-/ferri-cyanide chemistry) [44]. The total area-specific resistance (ASR) of a state-of-the-art RFB cell is mostly ohmic resistances, plus some minor contributions from kinetic and transport losses. Therefore, these large resistances not only represent significant performance losses, but they also have major economic consequences since they substantially impact power density, efficiency, and ultimately the cost of the reactor (the power delivered per unit area of reactor is inversely proportional to ASR [55]). The price of these membranes is also uncertain; although there is a sizable body of literature on ceramic membranes for water-treatment applications, a subset of which focus on the development of low-cost options ranging from as low as $25 \$ \mathrm{~m}^{-2}$ to $500 \$ \mathrm{~m}^{-2}$ [89-93]. At present, it is not clear how relevant these estimates are to the material sets conducive to use in RFBs, as application-specific design criteria vary (e.g., flexibility, conductivity, chemical compatibility, etc.).

While the lower bounds of the cost and ASR for SIC membranes have yet to be determined, one may use techno-economic analyses to estimate what values these parameters would need to be in order to present a competitive solution for RFBs. We estimate the LCOS as a function of ASR (Figure 4), which, as mentioned previously, linearly scales the reactor cost. We use the inputs for the infinite-lifetime species in Table 1, as SIC membranes are most effective for chemistries which experience losses that are dominated by crossover, and accordingly assume zero capacity fade (i.e., negligible capacity loss from non-crossover sources). We then vary the SIC membrane price between 100 and $300 \$ / \mathrm{m}^{2}$, which is within the range seen in water treatment literature and comparable to the present-day cost of Nafion [7,94]. We also vary two critical chemistrydependent parameters: active species cost (Figure 4a) and cell potential (Figure 4b). We find that LCOS is not particularly sensitive to active species cost and is more sensitive to membrane price, which makes sense as the reactor cost dominates the capital cost at high ASRs such that changes to electrolyte cost have a relatively small impact on both the capital cost and the LCOS. This is 
also why we find a strong LCOS sensitivity to cell potential (U), which scales both reactor costs $\left(\propto \mathrm{U}^{-2}\right)$ and energy costs $\left(\propto \mathrm{U}^{-1}\right)$. Thus, higher cell potentials can, at least partially, offset elevated cell ASRs. Reducing the measured ASR to $\sim 15 \Omega-\mathrm{cm}^{2}$ in RFB cells employing SIC membranes, a 6x reduction from published reports [44], may be technically achievable, but a viable implementation also requires a moderate cost for the SIC membrane (i.e., $\sim 100 \$ \mathrm{~m}^{-2}$ ) and a high voltage redox chemistry (i.e., $\geq 3 \mathrm{~V}$ ). Such requirements likely necessitate the use of non-aqueous electrolytes, which is still a nascent branch of RFB systems. Furthermore, such high ASRs create physical complications: a cell with an ASR of $15 \Omega-\mathrm{cm}^{2}$ would require $30 \times$ the area of a conventional cell configuration with a polymeric membrane like Nafion $\left(\sim 0.5 \Omega-\mathrm{cm}^{2}\right.$, for aqueous systems) for a given power output and chemistry, which is a substantial increase to the reactor footprint that must be considered. This may be less of an issue for long-duration applications, as the energy-capacity components increasingly dominate the system configuration. While the design space presented here suggests what a successful SIC membrane might look like, further studies of SIC membranes for RFBs, with particular focus on understanding tradeoffs between resistance, cost, and mechanical stability, are needed to more completely assess the viability of this approach.
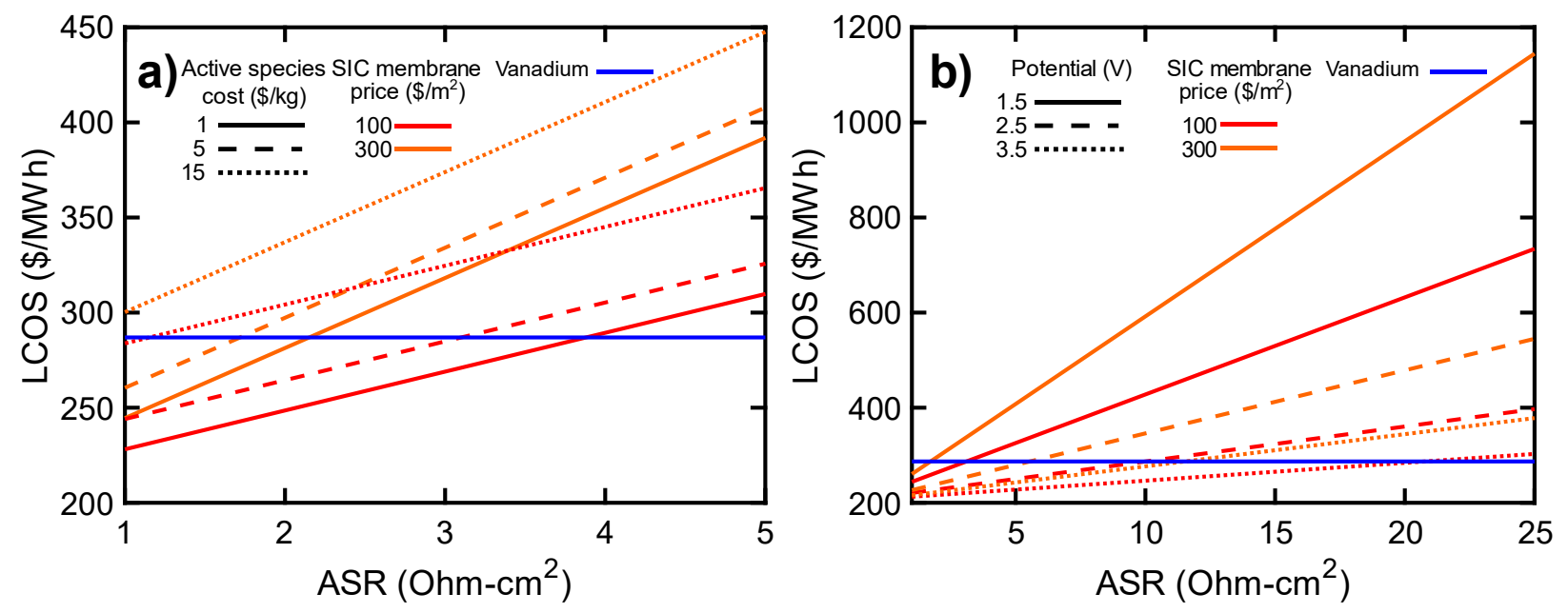

Figure 4 - LCOS as a function of the cell ASR, with membrane price (line colors), and active species cost (a, left) or potential (b, right) (line styles) as variable parameters. The left plot assumes a cell potential of $1.5 \mathrm{~V}$, and the right plot assumes an active species cost of $5 \mathrm{~kg}^{-1}$. The baseline LCOS of vanadium (assuming a potential of $1.4 \mathrm{~V}$, ASR of $0.5 \mathrm{ohm}-\mathrm{cm}^{2}$, active species cost of $\sim 30 \$ \mathrm{~kg}^{-1}$, and membrane cost of $300 \$ \mathrm{~m}^{-2}$ ) is plotted in blue. 


\section{Conclusions}

The desire for and research of potentially-inexpensive RFB chemistries has been growing in response to financial concerns around the cost of vanadium active species in the most mature RFB chemistry, the VRFB. However, these options present more challenges to consider beyond the alteration in cost of the electrolyte or even the kinetic, thermodynamic, and mass transport challenges of these new chemistries. As many of these new chemistries are asymmetric, the methods and associated costs of asymmetric capacity-loss remediation must be explored to determine if the complications that arise from cross-contamination outweigh the reduced capital cost relative to the more easily remediable VRFB. Accordingly, we have adapted our LCOS model, used in previous work for VRFBs, to evaluate two classes of asymmetric chemistries: those using active species of finite and infinite lifetimes. Finite-lifetime chemistries, often employing organic active species, primarily suffer capacity losses from active species decay, necessitating their periodic replacement. This can be achieved by performing total electrolyte replacement, or by selectively separating out and replacing or reusing the decayed species. We found that the separations route is substantially more economically effective, but only if such processes can be executed with low enough costs, and the LCOS of these systems is highly sensitive to the electrolyte cost and decay rate. We estimate that the cost to separate/recover/reuse should be limited to $\leq 10 \$ \mathrm{kWh}^{-1}$, and future work should explore electrolyte separation and recovery methods to better assess the feasibility of this target. This analysis has revealed an opportunity for chemical-manufacturing companies who may be uniquely positioned to design organic redox active species with decay remediation in mind as a key design criterion. Infinite-lifetime species primarily suffer capacity losses from crossover, which can be remediated by making the chemistry pseudo-symmetric via the spectator strategy or avoided altogether with the use of perfectly selective separators. The spectator strategy is only effective if the species are stable in their opposing half-cell's environments and if the resulting decrease in energy density and the increase in required active material do not increase the electrolyte cost above that of other potential symmetric chemistries like the VRFB; this requires active species with relatively low active species costs and/or equivalent weights $\left(\leq 15 \$ \mathrm{~kg}^{-1}\right.$ for active species $\sim 50$ grams per mole, or $\leq 5 \$$ $\mathrm{kg}^{-1}$ for active species $\sim 150$ grams per mole). We found that the Fe-Cr system, which has not been as widely studied or improved upon as compared to VRFBs, is a promising candidate chemistry 
for effective use of the spectator strategy to reduce the capital cost and the LCOS, as compared to the VRFB system. However, this case study highlights that, in order to reduce capital costs below $150 \$ \mathrm{kWh}^{-1}$, reductions in power costs (i.e., beyond choice of chemistry) are likely needed. Perfectly selective separators, likely ceramic-based materials, eliminate crossover at the expense of high cell resistances and power costs. The reduction in cell resistance needed to make this solution competitive seems feasible if the separator can be produced at sufficiently low costs and employed with high potential chemistries, as cell potential counters the effect of resistance on power costs and also reduces energy costs. This approach appears to be most suitable for nonaqueous electrolytes, where cell potentials $\geq 3 \mathrm{~V}$ are viable.

Looking forward, this LCOS model can be used as a framework to determine cost and performance targets for evaluating the techno-economic promise of new RFB chemistries and their potential capacity-loss remediation strategies. Future work will focus on expanding our treatment of capacity fade to encompass its dynamic nature, both in its mechanisms and rates, as a function of cell operating conditions (e.g., the application-informed duty cycle or temperature), cell components (e.g., choice of membrane or flow field), and electrolyte composition (e.g., choice of active or supporting species). This can be done by building on existing crossover and decay models to incorporate more fade mechanisms and power-dependence, and subsequently determining the inputs to these models for various chemistries. This will allow for a more accurate understanding of chemistry-dependent crossover, as well as evaluation of the efficacy of crossover remediation approaches (e.g., rebalancing or the spectator strategy).

\section{Credit authorship contribution statement}

Kara E. Rodby: Methodology, Software, Investigation, Formal analysis, Visualization, Writing original draft, Writing - review \& editing. Mike L. Perry: Conceptualization, Writing - review \& editing. Fikile R. Brushett: Conceptualization, Funding acquisition, Supervision, Writing original draft, Writing - review \& editing. 


\section{Acknowledgements}

This research was supported by grants through the MIT Energy Initiative and the MIT Deshpande Center for Technological Innovation. The authors thank Dr. Robert Darling of the Raytheon

Technologies Research Center (RTRC), Professor Michael Aziz and Dr. Marc-Antoni Goulet of Harvard University, and members of the Brushett research group for their insightful feedback on this work.

\section{References}

[1] Intergovernmental Panel on Climate Change, Global Warming of 1.5 C, 2018. https://www.ipcc.ch/sr15/.

[2] H. Zsiboracs, N. Hegedusne Baranyai, A. Vincze, L. Zentko, Z. Birkner, K. Mate, G. Pinter, Intermittent Renewable Energy Sources: The Role of Energy Storage in the European Power System of 2040, Electronics. 8 (2019) 729. https://doi.org/10.3390/electronics8070729.

[3] J.P. Barton, D.G. Infield, Energy storage and its use with intermittent renewable energy, IEEE Trans. Energy Convers. 19 (2004) 441-448. https://doi.org/10.1109/TEC.2003.822305.

[4] P. Denholm, Y. Sun, T. Mai, An Introduction to Grid Services: Concepts, Technical Requirements, and Provision from Wind, Denver, CO, 2019. https://www.nrel.gov/docs/fy19osti/72578.pdf.

[5] A.Z. Weber, M.M. Mench, J.P. Meyers, P.N. Ross, J.T. Gostick, Q. Liu, Redox flow batteries: A review, J. Appl. Electrochem. 41 (2011) 1137-1164. https://doi.org/10.1007/s10800-011-0348-2.

[6] T.M. Gür, Review of electrical energy storage technologies, materials and systems: Challenges and prospects for large-scale grid storage, Energy Environ. Sci. 11 (2018) 2696-2767. https://doi.org/10.1039/c8ee01419a.

[7] V. Viswanathan, A. Crawford, D. Stephenson, S. Kim, W. Wang, B. Li, G. Coffey, E. Thomsen, G. Graff, P. Balducci, M. Kintner-Meyer, V. Sprenkle, Cost and performance model for redox flow batteries, J. Power Sources. 247 (2014) 1040-1051. https://doi.org/10.1016/j.jpowsour.2012.12.023.

[8] B. Dunn, H. Kamath, J. Tarascon, Electrical energy storage for the grid: A battery of choices, Sci. Mag. 334 (2011) 928-936. https://doi.org/10.1126/science.1212741. 
[9] X.-Z. Yuan, C. Song, A. Platt, N. Zhao, H. Wang, H. Li, K. Fatih, D. Jang, A review of all-vanadium redox flow battery durability: Degradation mechanisms and mitigation strategies, Int. J. Energy Res. (2019) 1-40. https://doi.org/10.1002/er.4607.

[10] P. Alotto, M. Guarnieri, F. Moro, Redox flow batteries for the storage of renewable energy: A review, Renew. Sustain. Energy Rev. 29 (2014) 325-335. https://doi.org/10.1016/j.rser.2013.08.001.

[11] H. Prifti, A. Parasuraman, S. Winardi, T.M. Lim, M. Skyllas-Kazacos, Membranes for redox flow battery applications, Membranes (Basel). 2 (2012) 275-306. https://doi.org/10.3390/membranes2020275.

[12] Y. Zhang, L. Liu, J. Xi, Z. Wu, X. Qiu, The benefits and limitations of electrolyte mixing in vanadium flow batteries, Appl. Energy. 204 (2017) 373-381. https://doi.org/10.1016/j.apenergy.2017.07.049.

[13] R.A. Potash, J.R. McKone, S. Conte, H.D. Abruña, On the Benefits of a Symmetric Redox Flow Battery, J. Electrochem. Soc. 163 (2016) A338-A344. https://doi.org/10.1149/2.0971602jes.

[14] M.L. Perry, J.D. Saraidaridis, R.M. Darling, Crossover Mitigation Strategies for RedoxFlow Batteries, Curr. Opin. Electrochem. 21 (2020) 311-318. https://doi.org/10.1016/j.coelec.2020.03.024.

[15] M. Skyllas-Kazacos, L. Cao, M. Kazacos, N. Kausar, A. Mousa, Vanadium Electrolyte Studies for the Vanadium Redox Battery-A Review, ChemSusChem. 9 (2016) 15211543. https://doi.org/10.1002/cssc.201600102.

[16] J. Winsberg, C. Stolze, S. Muench, F. Liedl, M.D. Hager, U.S. Schubert, TEMPO/Phenazine Combi-Molecule: A Redox- Active Material for Symmetric Aqueous Redox- Flow Batteries, ACS Energy Lett. 1 (2016) 976-980. https://doi.org/10.1021/acsenergylett.6b00413.

[17] L. Tong, Y. Jing, R.G. Gordon, M.J. Aziz, Symmetric All-Quinone Aqueous Battery, ACS Appl. Energy Mater. 2 (2019) 4016-4021. https://doi.org/10.1021/acsaem.9b00691.

[18] G.D. Charlton, S.M. Barbon, J.B. Gilroy, C.A. Dyker, G.D. Charlton, S.M. Barbon, J.B. Gilroy, C.A. Dyker, A bipolar verdazyl radical for a symmetric all-organic redox flowtype battery, J. Energy Chem. 34 (2019) 52-56. https://doi.org/10.1016/j.jechem.2018.09.020.

[19] W. Duan, R.S. Vemuri, J.D. Milshtein, S. Laramie, R.D. Dmello, J. Huang, L. Zhang, D. $\mathrm{Hu}, \mathrm{M}$. Vijayakumar, W. Wang, J. Liu, R.M. Darling, L. Thompson, K. Smith, S. Moore, R. Brushett, X. Wei, A symmetric organic-based nonaqueous redox flow battery and its state of charge diagnostics by FTIR, J. Mater. Chem. A. 4 (2016) 5448-5456. https://doi.org/10.1039/c6ta01177b.

[20] Q. Liu, A.E.S. Sleightholme, A.A. Shinkle, Y. Li, L.T. Thompson, Non-aqueous vanadium acetylacetonate electrolyte for redox flow batteries, Electrochem. Commun. 11 (2009) 2312-2315. https://doi.org/10.1016/j.elecom.2009.10.006.

[21] M.H. Chakrabarti, R.A.W. Dryfe, E.P.L. Roberts, Evaluation of electrolytes for redox 
flow battery applications, 52 (2007) 2189-2195.

https://doi.org/10.1016/j.electacta.2006.08.052.

[22] H. Kim, T. Yoon, J. Jang, J. Mun, H. Park, J. Heon, S.M. Oh, A tetradentate Ni (II) complex cation as a single redox couple for non-aqueous flow batteries, J. Power Sources. 283 (2015) 300-304. https://doi.org/10.1016/j.jpowsour.2015.02.083.

[23] M.-A. Goulet, M.J. Aziz, Flow Battery Molecular Reactant Stability Determined by Symmetric Cell Cycling Methods, J. Electrochem. Soc. 165 (2018) A1466-A1477. https://doi.org/10.1149/2.0891807jes.

[24] Y.K. Zeng, T.S. Zhao, L. An, X.L. Zhou, L. Wei, A comparative study of all-vanadium and iron-chromium redox flow batteries for large-scale energy storage, J. Power Sources. 300 (2015) 438-443. https://doi.org/10.1016/j.jpowsour.2015.09.100.

[25] Vanadium Price, (2020). https://www.vanadiumprice.com/ (accessed August 1, 2020).

[26] US Geological Survey, Mineral Commodity Summaries 2020, 2020.

[27] D. Stringer, One Battery Material Sector Is Cheering For Lower Prices, Bloomberg. (2019). https://www.bloomberg.com/news/articles/2019-09-19/one-battery-materialsector-is-cheering-for-lower-prices.

[28] G. Williams, Vanadium Outlook 2019: After the "Year of Vanadium," What's Next?, Invest. News. (2018). https://investingnews.com/daily/resource-investing/battery-metalsinvesting/vanadium-investing/vanadium-outlook/ (accessed March 29, 2019).

[29] M.L. Perry, A.Z. Weber, Advanced Redox-Flow Batteries: A Perspective, J. Electrochem. Soc. 163 (2016) A5064-A5067. https://doi.org/10.1149/2.0101601jes.

[30] D.G. Kwabi, Y. Ji, M.J. Aziz, Electrolyte Lifetime in Aqueous Organic Redox Flow Batteries: A Critical Review, Chem. Rev. (2020). https://doi.org/10.1021/acs.chemrev.9b00599.

[31] L. Wei, M.C. Wu, T.S. Zhao, Y.K. Zeng, Y.X. Ren, An aqueous alkaline battery consisting of inexpensive all-iron redox chemistries for large-scale energy storage, Appl. Energy. 215 (2018) 98-105. https://doi.org/10.1016/j.apenergy.2018.01.080.

[32] V. Dieterich, J.D. Milshtein, J.L. Barton, T.J. Carney, R.M. Darling, Estimating the cost of organic battery active materials : a case study on anthraquinone disulfonic acid Estimating the cost of organic battery active materials : a case study on anthraquinone disulfonic acid, Transl. Mater. Res. (n.d.) aacb0e. https://doi.org/10.1088/20531613/aacb0e.

[33] Y.Y. Lai, X. Li, Y. Zhu, Polymeric Active Materials for Redox Flow Battery Application, ACS Appl. Polym. Mater. 2 (2020) 113-128. https://doi.org/10.1021/acsapm.9b00864.

[34] F.R. Brushett, M.J. Aziz, K.E. Rodby, On Lifetime and Cost of Redox-Active Organics for Aqueous Flow Batteries, ACS Energy Lett. 5 (2020) 879-884. https://doi.org/10.1021/acsenergylett.0c00140.

[35] M. Goulet, M.J. Aziz, Flow Battery Molecular Reactant Stability Determined by 
Symmetric Cell Cycling Methods, 165 (2018) 1466-1477.

https://doi.org/10.1149/2.0891807jes.

[36] M.A. Goulet, L. Tong, D.A. Pollack, D.P. Tabor, S.A. Odom, A. Aspuru-Guzik, E.E. Kwan, R.G. Gordon, M.J. Aziz, Extending the lifetime of organic flow batteries via redox state management, J. Am. Chem. Soc. 141 (2020) 8014-8019.

https://doi.org/10.1021/jacs.8b13295.

[37] S. Jin, E.M. Fell, L. Vina-Lopez, Y. Jing, P.W. Michalak, R.G. Gordon, M.J. Aziz, Near Neutral pH Redox Flow Battery with Low Permeability and Long-Lifetime Phosphonated Viologen Active Species, Adv. Energy Mater. 2000100 (2020) 1-10. https://doi.org/10.1002/aenm.202000100.

[38] M. Wu, Y. Jing, A.A. Wong, E.M. Fell, S. Jin, Z. Tang, R.G. Gordon, M.J. Aziz, Extremely Stable Anthraquinone Negolytes Synthesized from Common Precursors, Chem. (2020) 1-11. https://doi.org/10.1016/j.chempr.2020.03.021.

[39] Y.K. Zeng, X.L. Zhou, L. An, L. Wei, T.S. Zhao, A high-performance flow-field structured iron-chromium redox flow battery, J. Power Sources. 324 (2016) 738-744. https://doi.org/10.1016/j.jpowsour.2016.05.138.

[40] A. Dinesh, S. Olivera, K. Venkatesh, M.S. Santosh, M.G. Priya, Inamuddin, A.M. Asiri, H.B. Muralidhara, Iron-based flow batteries to store renewable energies, Environ. Chem. Lett. 16 (2018) 683-694. https://doi.org/10.1007/s10311-018-0709-8.

[41] L. Su, A.F. Badel, C. Cao, J.J. Hinricher, F.R. Brushett, Toward an Inexpensive Aqueous Polysulfide-Polyiodide Redox Flow Battery, Ind. Eng. Chem. Res. (2017) 9783-9792. https://doi.org/10.1021/acs.iecr.7b01476.

[42] X. Wei, G. Xia, B. Kirby, E. Thomsen, B. Li, Z. Nie, G.G. Graff, J. Liu, V. Sprenkle, W. Wang, An Aqueous Redox Flow Battery Based on Neutral Alkali Metal Ferri / ferrocyanide and Polysulfide Electrolytes, J. Electrochem. Soc. 163 (2016) 5150-5153. https://doi.org/10.1149/2.0221601jes.

[43] M.C. Wu, T.S. Zhao, H.R. Jiang, Y.K. Zeng, Y.X. Ren, High-performance zinc bromine flow battery via improved design of electrolyte and electrode, J. Power Sources. 355 (2017) 62-68. https://doi.org/10.1016/j.jpowsour.2017.04.058.

[44] E. Allcorn, G. Nagasubramanian, H.D.P. Iii, E. Spoerke, D. Ingersoll, Elimination of active species crossover in a room temperature, neutral $\mathrm{pH}$, aqueous flow battery using a ceramic NaSICON membrane, J. Power Sources. 378 (2018) 353-361. https://doi.org/10.1016/j.jpowsour.2017.12.041.

[45] Y. Wang, Y. Wang, H. Zhou, A Li - Liquid Cathode Battery Based on a Hybrid Electrolyte, ChemSusChem. 4 (2011) 1087-1090. https://doi.org/10.1002/cssc.201100201.

[46] N. Xu, X. Li, X. Zhao, J.B. Goodenough, K. Huang, A novel solid oxide redox flow battery for grid energy storage, Energy Environ. Sci. 4 (2011) 4942-4946. https://doi.org/10.1039/c1ee02489b.

[47] C. Stolze, C. Schmerbauch, C. Friebe, U.S. Schubert, A Tubular Polymer Redox Flow 
Battery with a Ceramic Membrane, Energy Technol. (2017) 225-227.

https://doi.org/10.1002/ente.201600304.

[48] Q. Huang, Q. Wang, Next-Generation, High-Energy-Density Redox Flow Batteries, Chempluschem. 80 (2015) 312-322. https://doi.org/10.1002/cplu.201402099.

[49] K.E. Rodby, T.J. Carney, Y. Ashraf Gandomi, J.L. Barton, R.M. Darling, F.R. Brushett, Assessing the levelized cost of vanadium redox flow batteries with capacity fade and rebalancing., J. Power Sources. 460 (2020) 227958.

https://doi.org/10.1016/j.jpowsour.2020.227958.

[50] US Department of Energy, Grid Energy Storage, 2013. https://www.energy.gov/sites/prod/files/2014/09/f18/Grid Energy Storage December 2013.pdf.

[51] ARPA-E, ARPA-E: The First Seven Years, 2016. https://arpae.energy.gov/sites/default/files/documents/files/Volume 1_ARPAE_ImpactSheetCompilation_FINAL.pdf.

[52] Lazard, Lazard's Levelized Cost of Storage Analysis - Version 4.0, 2018.

[53] Department of Energy, Levelized Cost of Energy (LCOE), (2015). https://www.energy.gov/sites/prod/files/2015/08/f25/LCOE.pdf (accessed February 7, 2019).

[54] M. Zheng, J. Sun, C. Meinrenken, T. Wang, Pathways towards enhanced techno-economic performance of flow battery systems in energy system applications, J. Electrochem.

Energy Convers. Storage. 16 (2019) 021001-1-021001-11.

https://doi.org/10.1115/1.4040921.

[55] R.M. Darling, K.G. Gallagher, J.A. Kowalski, H. Seungbum, F.R. Brushett, Pathways to low-cost electrochemical energy storage: a comparison of aqueous and nonaqueous flow batteries, Energy Environ. Sci. 7 (2014) 3459-3477. https://doi.org/10.1039/C4EE02158D.

[56] R.F. Gahn, N.H. Hagedorn, J.A. Johnson, Cycling Performace of the Iron- Chromium Redox Energy Storage System Conservation and Renewable Energy, Nasa Tm-87034. (1985).

[57] S. Wang, Z. Xu, X. Wu, H. Zhao, J. Zhao, J. Liu, Analyses and optimization of electrolyte concentration on the electrochemical performance of iron-chromium fl ow battery, Appl. Energy. 271 (2020) 115252. https://doi.org/10.1016/j.apenergy.2020.115252.

[58] US Geological Survey, Mineral Industry Surveys: Chromium, 2020.

[59] Z. Li, M.S. Pan, L. Su, P.C. Tsai, A.F. Badel, J.M. Valle, S.L. Eiler, K. Xiang, F.R. Brushett, Y.M. Chiang, Air-Breathing Aqueous Sulfur Flow Battery for Ultralow-Cost Long-Duration Electrical Storage, Joule. 1 (2017) 306-327. https://doi.org/10.1016/j.joule.2017.08.007.

[60] T.D. Gregory, M.L. Perry, P. Albertus, Cost and Price Projections of Synthetic Active Materials for Redox Flow Batteries, Prep. (2020). 
[61] J. Mellentine, Performance Characterization and Cost Assessment of an Iron Hybrid Flow Battery, Univ. Icel. (2011) 139. http://skemman.is/en/stream/get/1946/7698/20100/1/RES_Mellentine_Thesis_Paper_FIN AL.pdf.

[62] R. Darling, K. Gallagher, W. Xie, L. Su, F. Brushett, Transport Property Requirements for Flow Battery Separators, J. Electrochem. Soc. 163 (2016) A5029-A5040. https://doi.org/10.1149/2.0051601jes.

[63] KEMIWATT, (n.d.). https://kemiwatt.com/.

[64] Green Energy Storage, (n.d.). http://www.greenenergystorage.eu/en/battery/.

[65] CMBlu, (n.d.). https://www.cmblu.de/.

[66] XL Batteries, (n.d.). https://www.xl-batteries.com/.

[67] JenaBatteries, (n.d.). https://jenabatteries.de/en/.

[68] B. Huskinson, M.P. Marshak, C. Suh, S. Er, M.R. Gerhardt, C.J. Galvin, X. Chen, A. Aspuru-Guzik, R.G. Gordon, M.J. Aziz, A metal-free organic-inorganic aqueous flow battery, Nature. 505 (2014) 195-198. https://doi.org/10.1038/nature12909.

[69] US Department of Energy, DOE OE Global Energy Storage Database, (2020). https://www.sandia.gov/ess-ssl/global-energy-storage-database-home/ (accessed January 10, 2020).

[70] Y. Ji, M. Goulet, D.A. Pollack, D.G. Kwabi, S. Jin, D. De Porcellinis, E.F. Kerr, R.G. Gordon, M.J. Aziz, A Phosphonate-Functionalized Quinone Redox Flow Battery at NearNeutral pH with Record Capacity Retention Rate, Adv. Energy Mater. 9 (2019). https://doi.org/10.1002/aenm.201900039.

[71] D.G. Kwabi, K. Lin, Y. Ji, E.F. Kerr, M. Goulet, D. De Porcellinis, D.P. Tabor, D.A. Pollack, R.G. Gordon, Alkaline Quinone Flow Battery with Long Lifetime at pH 12, Joule. 2 (2018) 1907-1908. https://doi.org/10.1016/j.joule.2018.08.013.

[72] C.S. Sevov, R.E.M. Brooner, E. Chenard, R.S. Assary, J.S. Moore, J. Rodriguez-Lopez, M.S. Sanford, Evolutionary Design of Low Molecular Weight Organic Anolyte Materials for Applications in Nonaqueous Redox Flow Batteries, J. Am. Chem. Soc. 137 (2015) 14465-14472. https://doi.org/10.1021/jacs.5b09572.

[73] Z. Yang, L. Tong, D.P. Tabor, E.S. Beh, M. Goulet, D. De Porcellinis, A. Aspuru-guzik, R.G. Gordon, M.J. Aziz, Alkaline Benzoquinone Aqueous Flow Battery for Large-Scale Storage of Electrical Energy, Adv. Energy Mater. 8 (2018). https://doi.org/10.1002/aenm.201702056.

[74] J.D. Robert, M.C. Caserio, Separation, Purification, \& Identification of Organic Compounds, in: Basic Princ. Org. Chem., W.A. Benjamin, Inc., 1977.

[75] Y. Ren, X. Mao, T.A. Hatton, An Asymmetric Electrochemical System with Complementary Tunability in Hydrophobicity for Selective Separations of Organics, (2019). https://doi.org/10.1021/acscentsci.9b00379. 
[76] A.M. Grumezescu, ed., Water Purification, Academic Press, 2017.

[77] Q. Luo, L. Li, W. Wang, Z. Nie, X. Wei, B. Li, B. Chen, Z. Yang, V. Sprenkle, Capacity decay and remediation of nafion-based all-vanadium redox flow batteries, ChemSusChem. 6 (2013) 268-274. https://doi.org/10.1002/cssc.201200730.

[78] S. Rudolph, U. Schröder, I.M. Bayanov, On-line controlled state of charge rebalancing in vanadium redox flow battery, J. Electroanal. Chem. 703 (2013) 29-37. https://doi.org/10.1016/j.jelechem.2013.05.011.

[79] S. Roe, C. Menictas, M. Skyllas-Kazacos, A High Energy Density Vanadium Redox Flow Battery with 3 M Vanadium Electrolyte, J. Electrochem. Soc. 163 (2016) A5023-A5028. https://doi.org/10.1149/2.0041601jes.

[80] S. Corcuera, M. Skyllas-Kazacos, State-of-Charge Monitoring and Electrolyte Rebalancing Methods for the Vanadium Redox Flow Battery, Eur. Chem. Bull. 1 (2012) 511-519. https://doi.org/10.17628/ECB.2012.1.511.

[81] Y.K. Zeng, T.S. Zhao, L. An, X.L. Zhou, L. Wei, A comparative study of all-vanadium and iron-chromium redox flow batteries for large-scale energy storage, J. Power Sources. 300 (2015) 438-443. https://doi.org/10.1016/j.jpowsour.2015.09.100.

[82] Y.R. Dong, H. Kaku, K. Hanafusa, K. Moriuchi, T. Shigematsu, A Novel Titanium/Manganese Redox Flow Battery, ECS Trans. 69 (2015) 59-67. https://doi.org/10.1149/06918.0059ecst.

[83] B. Yang, A. Murali, A. Nirmalchandar, B. Jayathilake, G.K.S. Prakash, S.R. Narayanan, A Durable, Inexpensive and Scalable Redox Flow Battery Based on Iron Sulfate and Anthraquinone Disulfonic Acid, J. Electrochem. Soc. 167 (2020) 060520. https://doi.org/10.1149/1945-7111/ab84f8.

[84] R. Gahn, N. Hagedorn, J. Ling, Single Cell Performance Studies on the Fe / Cr Redox Energy Storage System Using Mixed Reactant Solutions at Elevated Temperature Conservation and Renewable Energy Division of Energy Storage Systems, Proc. Eighteenth Intersoc. Energy Convers. Eng. Conf. Orlando, FL, August 21-26, 1983. Vol. 4. (1983) 1647-1652.

[85] Y.S. Kim, S.H. Oh, E. Kim, D. Kim, S. Kim, C.H. Chu, K. Park, Iron-chrome crossover through nafion membrane in iron-chrome redox flow battery, Korean Chem. Eng. Res. 56 (2018) 24-28. https://doi.org/10.9713/kcer.2018.56.1.24.

[86] L. Su, J.A. Kowalski, K.J. Carroll, F.R. Brushett, Recent Developments and Trends in Redox Flow Batteries, in: Z. Zhang, S.S. Zhang (Eds.), Recharg. Batter. Mater. Technol. New Trends, Springer International Publishing, Cham, 2015: pp. 673-712. https://doi.org/10.1007/978-3-319-15458-9_24.

[87] B. Hu, J. Luo, C. DeBruler, M. Hu, W. Wu, T.L. Liu, Redox-Active Inorganic Materials for Redox Flow Batteries, in: H. Wang, B.P.T. Fokwa (Eds.), Inorg. Batter. Mater., Wiley, 2019: pp. 211-236.

[88] L. Zhang, Y. Qian, R. Feng, Y. Ding, X. Zu, C. Zhang, X. Guo, W. Wang, G. Yu, Reversible redox chemistry in azobenzene-based organic molecules for high-capacity and 
long-life nonaqueous redox flow batteries, Nat. Commun. 11 (2020) 3843. https://doi.org/10.1038/s41467-020-17662-y.

[89] D. Ghosh, M.K. Sinha, M.K. Purkait, A comparative analysis of low-cost ceramic membrane preparation for effective fl uoride removal using hybrid technique, Desalination. 327 (2013) 2-13. https://doi.org/10.1016/j.desal.2013.08.003.

[90] B.K. Nandi, R. Uppaluri, M.K. Purkait, Treatment of Oily Waste Water Using Low-Cost Ceramic Membrane : Flux Decline Mechanism and Economic Feasibility, Sep. Sci. Technol. 44 (2009) 2840-2869. https://doi.org/10.1080/01496390903136004.

[91] B.K. Nandi, A. Moparthi, R. Uppaluri, M.K. Purkait, Treatment of oily wastewater using low cost ceramic membrane : Comparative assessment of pore blocking and artificial neural network models, Chem. Eng. Res. Des. 88 (2009) 881-892. https://doi.org/10.1016/j.cherd.2009.12.005.

[92] S.K. Hubadillah, Z. Harun, M.H.D. Othman, A.F. Ismail, W.N.W. Salleh, H. Basri, M.Z. Yunos, P. Gani, Preparation and characterization of low cost porous ceramic membrane support from kaolin using phase inversion / sintering technique for gas separation : Effect of kaolin content and non-solvent coagulant bath, Chem. Eng. Res. Des. 112 (2016) 2435. https://doi.org/10.1016/j.cherd.2016.06.007.

[93] R.V. Kumar, L. Goswami, K. Pakshirajan, G. Pugazhenthi, Dairy wastewater treatment using a novel low cost tubular ceramic membrane and membrane fouling mechanism using pore blocking models, J. Water Process Eng. 13 (2016) 168-175. https://doi.org/http://dx.doi.org/10.1016/j.jwpe.2016.08.012.

[94] C. Minke, T. Turek, Economics of vanadium redox flow battery membranes, J. Power Sources. 286 (2015) 247-257. https://doi.org/10.1016/j.jpowsour.2015.03.144. 